\title{
Influence of Diabetes on the Outcome of Acute Coronary Syndrome in Kuwait
}

\author{
Hisham Saad ${ }^{a}$ Sana Sawan $^{\text {a }}$ Wafa Rashed $^{\mathrm{a}}$ Mohammad Zubaid $^{\mathrm{b}}$ \\ Department of Medicine, ${ }^{\mathrm{a} M u b a r a k}$ Al-Kabeer Hospital and ${ }^{\mathrm{b}}$ Faculty of Medicine, Kuwait University, Kuwait
}

\author{
Key Words \\ Acute myocardial infarction - Diabetes mellitus • \\ Coronary artery disease - Kuwait Acute Coronary \\ Syndrome Registry
}

\begin{abstract}
Objectives: To describe the baseline characteristics and management of patients with and without diabetes mellitus (DM) hospitalized with acute myocardial infarction (AMI) and to assess the influence of DM on hospital outcomes and hospital mortality. Subjects and Methods: We analyzed data from a 6-month observational study (Kuwait Acute Coronary Syndrome Registry) of unselected patients admitted with a diagnosis of AMI over a period of 6 months, from December 2003 through May 2004. Results: Of 1,295 patients enrolled, 609 (47\%) were diabetics and 686 (53\%) were non-diabetics. Diabetics were more likely to have a past history of coronary artery disease, hypertension and left ventricular systolic dysfunction than non-diabetics. There was less use of $\beta$-blockers and aspirin in diabetics as compared to non-diabetics (62 vs. $71 \%$ and 95.5 vs. $97.9 \%, p<0.03$, for $\beta$-blockers and aspirin, respectively). Left ventricular failure and cardiogenic shock occurred more often in diabetics compared to nondiabetics ( 16 vs. $7 \%$ and 5 vs. $3 \%, p<0.001$, for left ventricular failure and shock, respectively). The mortality rate was $6 \%$ for diabetics and $2 \%$ for non-diabetics ( $p<0.001$ ). Conclusion: DM is a major health problem among the adult population in Kuwait, and almost half the AMI population suffer from diabetes. Diabetic patients had higher rates of complications, especially left ventricular failure and cardiogenic
\end{abstract}

shock, as compared to non-diabetic patients. The in-hospital mortality among diabetics with AMI was almost triple that of non-diabetics. The results of this study highlight the need to improve adherence to evidence-based treatment in diabetic patients with AMI. Copyright $\odot 2010$ S. Karger AG, Basel

\section{Introduction}

Diabetes mellitus (DM) is a major risk factor for coronary artery disease (CAD). Due to its prognostic significance, the most recent National Cholesterol Education Program III guidelines classified it as a coronary disease equivalent [1]. A previous study has shown that diabetics have higher mortality and morbidity rates compared to non-diabetics after acute myocardial infarction (AMI) [2].

Prior to the advent of thrombolytic therapy, studies of patients with DM showed a greater than 2-fold increase in mortality in men [3], and an even higher rate in women compared with their non-diabetic counterparts [4]. In the thrombolytic era, epidemiological studies, including randomized trials, have demonstrated that hospital mortality remains 1.5-2 times higher among patients with DM [5]. Only a few studies have reported on the prognosis of diabetics with non-ST-segment elevation myocardial infarction, as exemplified by Malmberg et al. [6] who demonstrated that DM predicts a worse outcome.

Diabetes is a major health problem in Kuwait; its prevalence has increased dramatically and is now reported to

\section{KARGER \\ Fax +4161306 1234 \\ E-Mail karger@karger.ch}

www.karger.com
(C) 2010 S. Karger AG, Basel

$1011-7571 / 10 / 0192-0113 \$ 26.00 / 0$

Accessible online at:

www.karger.com/mpp
Prof. Mohammad Zubaid

Department of Medicine, Faculty of Medicine

PO Box 24923, Safat 13110 (Kuwait)

Tel. +965 2531 9596, Fax +965 25338907

E-Mail zubaid@hsc.edu.kw 
be present in about $15 \%$ of the adult population [7]. We aimed to describe the baseline characteristics and management of patients with and without DM hospitalized with AMI, and to assess the influence of DM on hospital outcomes and hospital mortality.

\section{Subjects and Methods}

We analyzed data from a nationwide prospective observational study (Kuwait Acute Coronary Syndrome Registry) [8] of unselected patients admitted over a period of 6 months, from December 2003 through May 2004. Consecutive patients were recruited from all 7 general hospitals in Kuwait. These hospitals are: Mubarak Al-Kabeer, Al-Amiri, Al-Adan, Al-Farwania, Al-Jahra, Al-Sabah, and Kuwait Oil Company. 97\% of variables collected were available for analysis. Almost all consecutive patients were included, as every effort was made to enroll all consecutive patients admitted to hospital with a provisional diagnosis of acute coronary syndrome. Approval of the ethics board was obtained. Patients' identities were not revealed on the case report forms (CRFs), as they were identified on the CRFs by initials and file numbers only. We did not carry out any intervention (e.g. extra history taking or blood sampling) other than what is normally carried out for such patients. The management of each individual patient was left entirely up to the discretion of the treating physician. The registry was funded by the Merck Sharp and Dohme pharmaceutical company and the Kuwait Oil Company. The sponsors had no influence on the study design, data collection, entry and analysis or writing of this paper.

Data were collected using a structured CRF. This form included information on patients' demographics, past medical history, risk factors, physical examination, ECG at presentation, cardiac enzymes, blood glucose at admission, lipid profile, admission and discharge diagnosis, thrombolytic therapy administration, and hospital course and outcomes. The CRFs were checked for completeness and returned to the investigators for responses to data queries. However, we did not carry out site visits for data source verification.

The diagnosis of AMI was based on the definitions made by the American College of Cardiology in their clinical data standards document [9]. Briefly, a diagnosis of AMI was made when there was elevation of troponin I or creatinine kinase (2 or more times the normal value with at least $3 \% \mathrm{MB}$ fraction) with at least one of the following two criteria: ischemic type chest pain or diagnostic serial ECG changes (e.g. development of pathological Q waves or ECG changes indicative of ischemia, like ST-segment elevation or depression). Patients were considered to be diabetic if they had been told by a physician to have the disease or if they were on any treatment including a diabetic diet, antidiabetic agents or insulin therapy.

\section{Statistical Analysis}

Baseline clinical characteristics of patients were presented as frequencies and means. Continuous variables were compared using the Mann-Whitney U test and categorical variables were compared using the Z-test of proportion; a value of $\mathrm{p}<0.05$ was considered statistically significant. All data analyses were carried out using SPSS version 10.0.

\section{Results}

\section{Patient Characteristics}

Of 1,295 patients enrolled, 609 (47\%) were diabetics, whereas 686 (53\%) were non-diabetics. The baseline characteristics and risk factors are listed in table 1. Diabetic patients were older, with a mean age of $60 \pm 11.1$ years compared to a mean age of $52.1 \pm 12.2$ years for non-diabetics $(\mathrm{p}<0.001)$. There was higher proportion of females in the diabetic group. Diabetics were more likely to have a past history of CAD, hypertension and left ventricular systolic dysfunction than non-diabetics. ST-segment elevation was found in only $42 \%$ of diabetic patients, in contrast to $60 \%$ of non-diabetic patients. The mean blood sugar at presentation (random) for diabetics was higher than for non-diabetics (14 vs. $7 \mathrm{mmol} / \mathrm{l})$.

\section{Management Practice}

The hospital and discharge medications are given in table 2. Irrespective of their diabetic status, almost all patients were prescribed heparin (the majority of patients received unfractionated heparin, $84.4 \%$ for diabetics vs. $87.4 \%$ for non-diabetics, whereas the minority received low-molecular-weight heparin, 9.5\% for diabetics vs. $8.5 \%$ for non-diabetics), while very few were prescribed clopidogrel and glycoprotein IIb/IIIa inhibitors. Thrombolytic therapy was used less in diabetics compared to non-diabetics ( 66.5 vs. $80.4 \%, \mathrm{p}<0.001)$. The thrombolytic agents that were administered were reteplase, streptokinase and tenecteplase (tissue plasminogen activator). The rate of cardiac catheterization during hospitalization was $18 \%$ for both diabetics and non-diabetics. $\beta$-Blockers and aspirin were used less in diabetics compared to non-diabetics ( 62 vs. $71 \%$ and 95.5 vs. $97.9 \%$, $\mathrm{p}<0.001$ and $\mathrm{p}=0.03$, for $\beta$-blockers and aspirin, respectively).

At discharge, angiotensin-converting enzyme inhibitors (ACEIs)/angiotensin receptor blockers (ARBs) and statins were prescribed more often to diabetics as compared to non-diabetics (70 vs. $56 \%$ and 70 vs. $55 \%$, for ACEIs/ARBs and statins, respectively, $\mathrm{p}<0.001$ for both). At discharge from hospital, calcium channel blockers were prescribed more often to diabetics as compared to non-diabetics ( 20.2 vs. $12.6 \%, \mathrm{p}<0.001)$.

\section{Hospital Outcome}

Hospital outcomes are listed in table 3. Left ventricular failure and cardiogenic shock occurred more often in diabetics compared to non-diabetics (16 vs. $7 \%$ and 5 vs. 
Table 1. Baseline patient characteristics

\begin{tabular}{|c|c|c|c|}
\hline & $\begin{array}{l}\text { Diabetics } \\
(\mathrm{n}=609)\end{array}$ & $\begin{array}{l}\text { Non-diabetics } \\
(\mathrm{n}=686)\end{array}$ & $\begin{array}{l}\mathrm{p} \\
\text { value }\end{array}$ \\
\hline \multicolumn{4}{|l|}{ Age } \\
\hline Mean $\pm S D$, years & $60.1 \pm 11.9$ & $52.1 \pm 12.2$ & $<0.001$ \\
\hline Median, years & 60 & 50 & \\
\hline$\leq 75$ years & $536(88.0)$ & $642(93.6)$ & $<0.001$ \\
\hline$>75$ years & $73(12.0)$ & $43(6.3)$ & $<0.001$ \\
\hline Male gender & $434(71.3)$ & $620(90.4)$ & $<0.001$ \\
\hline Kuwaiti citizens & $305(50.1)$ & $174(25.4)$ & $<0.001$ \\
\hline \multicolumn{4}{|l|}{ History of CAD } \\
\hline Angina & $266(43.7)$ & $165(24.0)$ & $<0.001$ \\
\hline Myocardial infarction & $189(31.0)$ & $143(20.8)$ & $<0.001$ \\
\hline Percutaneous coronary intervention & $59(9.7)$ & $34(4.9)$ & $<0.001$ \\
\hline Coronary artery bypass grafting & $60(9.8)$ & $10(1.4)$ & $<0.001$ \\
\hline Hypertension & $373(61.2)$ & $185(27.0)$ & $<0.001$ \\
\hline Left ventricular failure at presentation & $182(29.9)$ & $79(11.5)$ & $<0.001$ \\
\hline ST-segment elevation at presentation & $256(42.0)$ & $415(60.5)$ & $<0.001$ \\
\hline Blood sugar level at presentation, $\mathrm{mmol} / \mathrm{l}$ & $14.8 \pm 6.4$ & $8.2 \pm 3.8$ & $<0.001$ \\
\hline
\end{tabular}

Figures in parentheses are percentages.

$3 \%$ for left ventricular failure and shock, respectively, $\mathrm{p}<$ 0.001 for both). Stroke was a rare event in all patients. The rate of coronary angiography and the median length of hospital stay was almost the same for both groups. The mortality rate was $6 \%$ for diabetic patients and $2 \%$ for non-diabetic patients $(\mathrm{p}<0.001)$.

\section{Discussion}

Our study showed that differences exist between myocardial infarction patients with and without diabetes in regards to characteristics, management and outcomes. The findings of our study are consistent with those of prior studies showing that diabetic patients with AMI are older [2,10], more often women [2], more likely to be hypertensive [10], and more likely to have a history of angina [2, 10] and congestive heart failure [2].

We found less use of thrombolytic therapy among diabetic patients with ST-segment elevation myocardial infarction compared to non-diabetic patients. This is in agreement with Hansen et al. [11]. Possible explanations for less thrombolysis in diabetics are late presentation, atypical symptoms due to neuropathy [12] and a higher proportion of females, especially as we know that women seek medical attention later than men when suffering from cardiovascular symptoms [13].
Table 2. Use of medications in the first $24 \mathrm{~h}$ of admission and at discharge

\begin{tabular}{lccr}
\hline Characteristics & Diabetics & $\begin{array}{l}\text { Non- } \\
\text { diabetics }\end{array}$ & \multicolumn{1}{l}{$\begin{array}{l}\mathrm{p} \\
\text { value }\end{array}$} \\
\hline First 24 h after admission & $\mathrm{n}=609$ & $\mathrm{n}=686$ & \\
Aspirin & $583(95.7)$ & $267(97.9)$ & 0.035 \\
Clopidogrel & $34(5.6)$ & $20(2.9)$ & 0.222 \\
B-Blockers & $376(61.7)$ & $487(71.0)$ & $<0.001$ \\
Calcium blockers & $74(12.2)$ & $55(8)$ & $<0.015$ \\
Lysis in eligible patients ${ }^{2}$ & $218(66.5)$ & $265(80.4)$ & $<0.001$ \\
Intravenous heparin & $520(84.4)$ & $603(87.4)$ & 0.081 \\
LMWH & $58(9.5)$ & $58(8.5)$ & 0.595 \\
GPI & $13(2.1)$ & $16(2.3)$ & 0.956 \\
\hline At hospital discharge (alive) & $\mathrm{n}=573$ & $\mathrm{n}=668$ & \\
Aspirin & $549(95.8)$ & $647(96.8)$ & 0.433 \\
Clopidogrel & $72(12.6)$ & $50(7.5)$ & 0.003 \\
B-Blockers & $430(75.0)$ & $554(82.9)$ & $<0.001$ \\
Calcium blockers & $116(20.2)$ & $84(12.6)$ & $<0.001$ \\
ACEIs/ARBs & $398(69.4)$ & $375(56.1)$ & $<0.001$ \\
Statins & $398(69.4)$ & $366(54.8)$ & $<0.001$ \\
\hline
\end{tabular}

Figures in parentheses are percentages. GPI $=$ Glycoprotein IIb/IIIa inhibitors; ACEIs/ARBs = angiotensin-converting enzyme inhibitors/angiotensin receptor blockers.

${ }^{1}$ Patients with ST-segment elevation and left bundle branch block, with symptom onset $\leq 12 \mathrm{~h}$ without contraindication. 
Table 3. Hospital outcomes of patient populations

\begin{tabular}{lccc}
\hline Characteristics & $\begin{array}{l}\text { Diabetics } \\
(\mathrm{n}=609 ; 47 \%)\end{array}$ & $\begin{array}{c}\text { Non-diabetics } \\
(\mathrm{n}=686 ; 53 \%)\end{array}$ & $\begin{array}{c}\mathrm{p} \\
\text { value }\end{array}$ \\
\hline Recurrent ischemia & $126(20.7)$ & $135(19.7)$ & 0.705 \\
Re-infarction & $18(2.9)$ & $21(3.1)$ & 0.962 \\
Left ventricular failure & $97(15.9)$ & $49(7.1)$ & $<0.001$ \\
Cardiogenic shock & $32(5.2)$ & $20(2.9)$ & 0.049 \\
Stroke & $3(0.5)$ & $1(0.1)$ & 0.415 \\
Hospital cardiac catheterization & $113(18.5)$ & $126(18.4)$ & 0.979 \\
Duration of hospital stay (median), days & 6 & 6 & $\mathrm{NS}$ \\
Hospital mortality & $36(5.9)$ & $14(2.0)$ & $<0.001$ \\
\hline
\end{tabular}

Figures in parentheses are percentages.

The underuse of $\beta$-blockers in our diabetic patients was in concordance with a prior study [2]. The reason for that may be the misconception held by many physicians that $\beta$-blockers are considered harmful in diabetics as they mask hypoglycemic symptoms and exacerbate impaired glucose tolerance. We found more use of ACEIs/ ARBs in diabetic patients as compared to non-diabetic counterparts; this was also observed by Galcera-Tomas et al. [2]. This reflects physicians' awareness of the benefits of ACEIs after AMI, especially in diabetics. ACEIs have proven beneficial in patients with diabetes as they reduce subsequent major cardiovascular events and slow myocardial remodeling. ACEIs are also prescribed for diabetics to slow the progression of diabetic nephropathy.

We also showed that diabetic patients had higher rates of complications, especially left ventricular failure and cardiogenic shock, which is in agreement with other studies [11, 14]. This could be explained by a previously depressed systolic function due to a greater prevalence of hypertension in diabetics. In addition, diabetes is associated with severer CAD [14], with impairment of regional left ventricular function in non-infarct-related areas [14], left ventricular diastolic dysfunction [15], impaired reflex adaptation to hemodynamic stress and occult cardiomyopathy [15].

The hospital mortality among diabetic patients with AMI was found to be almost triple that of non-diabetic patients in our study. This is higher than reported by Granger et al. [14]. There are several explanations for this finding. First, diabetic patients had a worse risk profile as they were older, more often females, more often hypertensive and more often had previous CAD. Second, diabetic patients received less thrombolysis. Last, diabetics had higher levels of blood glucose at admission, and hy- perglycemia is known to be an independent predictor of cardiovascular death [16].

A limitation of our study is the fact that the classification of patients as diabetics or non-diabetics was based on information reported by the patients or their relatives. Therefore, patients with undiagnosed diabetes may have been misclassified. However, this would underestimate the effect of diabetes rather than overestimate it. No data were available regarding diabetes duration, antidiabetic agents use, or intensity of glycemic control.

\section{Conclusion}

$\mathrm{DM}$ is a major health problem among the adult population in Kuwait, and almost half the AMI population suffer from diabetes. Diabetic patients had higher rates of complications, especially left ventricular failure and cardiogenic shock, as compared to non-diabetic patients. The in-hospital mortality among diabetics with AMI was almost triple that of non-diabetics. The results of this study highlight the need to improve adherence to evidence-based treatment in diabetic patients with AMI.

\section{Acknowledgement}

The authors would like to thank Miss Rihab Moneer, MSC, for her valuable contributions to data analysis. 


\section{References}

$>1$ Expert Panel on Detection, Evaluation, and Treatment of High Blood Cholesterol in Adults: Executive Summary of The Third Report of The National Cholesterol Education Program (NCEP) Expert Panel on Detection, Evaluation, and Treatment of High Blood Cholesterol in Adults (Adult Treatment Panel III). JAMA 2001;285:24862497.

-2 Galcera-Tomas J, Melgarejo-Moreno A, Garcia-Alberola A, Rodriguez-Garcia P, Lozano-Martinez J, Martinez-Hemandez J, Martinez-Femandez S: Prognostic significance of diabetes in acute myocardial infarction: are the differences linked to female gender? Int J Cardiol 1999;69:289-298.

$>3$ Malmberg K, Ryden L: Myocardial infarction in patients with diabetes mellitus. Eur Heart J 1988;9:259-264.

4 Jaffe AS, Spadaro JJ, Schechtman K, Roberts R, Geltman EM, Sobel BE: Increased congestive heart failure after myocardial infarction of modest extent in diabetes mellitus patients. Am Heart J 1984;108:31-37.

$\checkmark 5$ Murcia AM, Hennekens CH, Lamas GA, Jimenez-Navarro M, Rouleau JL, Flaker GC, Goldman S, Skali H, Braunwald E, Pfeffer MA: Impact of diabetes on mortality in patients with myocardial infarction and left ventricular dysfunction. Arch Intern Med 2004;164:2273-2274.

6 Malmberg K, Yusuf S, Gerstein H, Brown J, Zhao F, Hunt D, Piegas L, Calvin J, Keltai M, Budaj A: OASIS Registry Investigators: impact of diabetes on long-term prognosis in patients with angina and non-Q-wave myocardial infarction: results of the OASIS Registry. Circulation 2000;102:1014-1019.
$>7$ Abdella N, Al Arouj M, Al Nakhi A, Al Assoussi A, Moussa M: Non-insulin-dependent diabetes in Kuwait: prevalence rates and associated risk factors. Diabetes Res Clin Pract 1998;42:187-196.

$>8$ Zubaid M, Rashed W, Saad H, Attiya A, Abu Al-Banat B, Ridha M, Al-Kandari M, Baidas G, Al-Hamdan R, Zubair S, Talib L: Kuwait Acute Coronary Syndromes Registry: baseline characteristics, management practices and in-hospital outcomes of patients hospitalized with acute coronary syndromes in Kuwait. Med Princ Pract 2007; 16:407-412.

$\checkmark 9$ Cannon CP, Battler A, Brindis RG, Cox JL, Ellis SG, Every NR, Flaherty JT, Harrington RA, Krumholz HM, Simoons ML, Van De Werf FJ, Weintraub WS, Mitchell KR, Morrisson SL, Brindis RG, Anderson HV, Cannom DS, Chitwood WR, Cigarroa JE, Collins-Nakai RL, Ellis SG, Gibbons RJ, Grover FL, Heidenreich PA, Khandheria BK, Knoebel SB, Krumholz HL, Malenka DJ, Mark DB, Mckay CR, Passamani ER, Radford MJ, Riner RN, Schwartz JB, Shaw RE, Shemin RJ, Van Fossen DB, Verrier ED, Watkins MW, Phoubandith DR, Furnelli T: American College of Cardiology key data elements and definitions for measuring the clinical management and outcomes of patients with acute coronary syndromes. A report of the American College of Cardiology Task Force on Clinical Data Standards (Acute Coronary Syndromes Writing Committee). J Am Coll Cardiol 2001;38:2114-2130.
10 Herlitz J, Malmberg K, Karlson BW, Ryden L, Hjalmarson A: Mortality and morbidity during a five-year follow-up of diabetics with myocardial infarction. Acta Med Scand 1998;224:31-38.

11 Hansen HH, Kjaergaard SC, Bulow I, Fog L, Christensen PD: Thrombolytic therapy in diabetic patients with acute myocardial infarction. Diabetes Care 1996;19:1135-1137.

12 Valensi P, Sachs RN, Harfouche B, Paries J, Cosson E, Paycha F: Predictive value of cardiac autonomic neuropathy in diabetic patients with or without silent myocardial ischemia. Diabetes Care 2001;24:339-343.

13 Council on Ethics and Judicial Affairs, American Medical Association: Gender disparities in clinical decision making. J Am Med Assoc 1991;266:559-562.

14 Granger CB, Califf RM, Young S, Candela R, Samaha J, Worley S, Kereiakes DJ, Topol EJ: Outcome of patients with diabetes mellitus and acute myocardial infarction treated with thrombolytic agents. J Am Coll Cardiol 1993; 21:920-925.

15 Jacoby RM, Nesto RW: Acute myocardial infarction in the diabetic patient: pathophysiology, clinical course and prognosis. J Am Coll Cardiol 1992;20:736-744.

16 Yudkin JS, Blauth C, Drury P, Fuller J, Henley J, Lancaster T, Lankester J, Lean M, Pentecost B, Press V, Rothman D: Prevention and management of cardiovascular disease in patients with diabetes mellitus: an evidence base. Diabet Med 1996;13(suppl):101121. 